[4] Goekoop-Ruiterman YPM, de Vries-Bouwstra JK, Allaart CF, et al. (2008) Clinical and radiographic outcomes of four different treatment strategies in patients with early rheumatoid arthritis (the BeSt study): A randomized, controlled trial. Arthritis Rheum 58:S126-35. doi: 10.1002/art.23364.

Acknowledgements: We would like to thank all the patients, rheumatology nurses, and rheumatologists who participated in our study.

Disclosure of Interest: None declared

DOI: 10.1136/annrheumdis-2017-eular.1638

\section{THU0072 RISK OF REVISION, PROSTHETIC JOINT INFECTION AND DEATH FOLLOWING TOTAL HIP OR KNEE ARTHROPLASTY IN PATIENTS WITH RHEUMATOID ARTHRITIS - A NATIONWIDE COHORT STUDY FROM DENMARK}

R.L. Cordtz ${ }^{1,2}$, L.E. Kristensen ${ }^{2}$, S. Overgaard ${ }^{3}$, A. Odgaard ${ }^{4}$, H. Lindegaard ${ }^{5}$, L. Dreyer ${ }^{1,2},{ }^{1}$ Center for Rheumatology and Spine Diseases, Gentofte, Rigshospitalet; ${ }^{2}$ The Parker Institute, Bispebjerg and Frederiksberg Hospital, Copenhagen; ${ }^{3}$ Dept. of Orthopaedic Surgery and Traumatology, Odense University Hospital, Odense; ${ }^{4}$ Dept. of Orthopaedics, Herlev and Gentofte Hospital, Copenhagen; ${ }^{5}$ Dept. of Rheumatology, Odense University Hospital, Odense, Denmark

Background: Studies have shown that rheumatoid arthritis (RA) patients are at increased risk of prosthetic joint infection (PJI) but with non-uniform results for mortality risk, following total hip and knee arthroplasty (THA and TKA, respectively). The impact of biological DMARD (bDMARD) treatment on the risk of these outcomes is unknown.

Objectives: To investigate the risk of revision, PJI and death following THA and TKA in 1) RA compared with osteoarthritis (OA) patients and 2) RA patients treated with bDMARDs compared with those not.

Methods: Register-based cohort study linking the National Patient Register, DANBIO, Danish Hip Arthroplasty Register and Danish Knee Arthroplasty Register.

Follow-up: from date of THA/TKA to date of any of the outcomes, to 10 years of follow-up or end of 2014, whichever came first.

Statistics: Fine-Gray competing risks analyses to calculate confounder adjusted sub-Hazard Ratios (aSHR) with 95\% confidence intervals $(95 \% \mathrm{Cl}$ ) for revision and PJI; Cox proportional hazard models to calculate aHR for risk of death.

Results: We identified 3913 RA and 120499 OA patients. In DANBIO, 360 bDMARD and 1586 not-bDMARD treated RA patients were eligible for analysis. See Table for results.

Conclusions: We report an increased risk of death and PJI but a lower risk of revision in patients with RA compared with OA following THA and TKA. In RA patients, prednisolone, but not bDMARD treatment within the year prior and/or following THA and TKA was associated with an increased risk of death.

Disclosure of Interest: R. Cordtz: None declared, L. E. Kristensen: None declared, S. Overgaard Speakers bureau: Pfizer, AbbVie, Amgen, UCB, Celgene, BMS, MSD, Novartis, Eli Lilly, Janssen Pharmaceuticals, A. Odgaard: None declared, H. Lindegaard: None declared, L. Dreyer Consultant for: LD has received fees for speaking and consultancy by MSD, UCB and Janssen pharmaceuticals. DOI: 10.1136/annrheumdis-2017-eular.1742

\section{THU0073 FACTORS ASSOCIATED WITH TREATMENT ADHERENCE IN RHEUMATOID ARTHRITIS: A SYSTEMATIC LITERATURE REVIEW}

E.T. Goh ${ }^{1}$, A.J.X. Soo ${ }^{1}$, J. Galloway ${ }^{2}$, S. Norton ${ }^{2}$, E. Nikiphorou ${ }^{2} .{ }^{1}$ University College London; ${ }^{2}$ King's College London, London, United Kingdom

Background: Nonadherence to treatment in rheumatoid arthritis (RA) has been shown to negatively impact on treat to target goals and disease outcomes. Identifying and targeting potential factors influencing nonadherence is therefore crucial in optimising patient management.

Objectives: To determine factors associated with nonadherence in patients with RA.

Methods: An electronic search was performed by two independent reviewers using MEDLINE and focusing on articles published from inception to January 2017. The search strategy combined the thesaurus (MeSH) and expanded keyword searches of two concepts: RA and treatment adherence. Inclusion criteria included observational studies and clinical trials examining potential factors associated with nonadherence. Exclusion criteria included articles not in English or without online access and those with a focus on forms of therapy other than medication. Agreement between raters at the screening stage was high $(97 \%$, kappa $=.87)$.

Results: The primary search yielded 1411 papers, from which 75 were eventually identified as suitable for full review (Figure). Of the 75 papers, 65 were based on observational studies and 10 on clinical trials. Factors associated with nonadherence were broadly categorized into patient-related factors (socio-demographic factors, patient perceptions [beliefs/knowledge/attitudes]), disease-related factors (disease duration/severity, comorbidities, functional disability) and treatmentrelated factors (drug type/ method of administration/duration/regimen complexity, combination therapy). The majority ( $70 \%$ of all included studies) of studies reported significant associations between patient-driven factors and nonadherence. Adherence was found to be negatively associated with socioeconomic status, health literacy, and beliefs/perceptions/knowledge of the disease and treatment. Studies reported poorer mental health state $(n=6)$ and greater disability/pain $(n=7)$ to be implicated in nonadherence. Disease duration was largely non-significant in treatment adherence, although a few studies reported a negative correlation $(n=3)$. Combining biologics with DMARDs was associated with improved adherence. However, considering non-biologic DMARDs only, adherence rates were higher amongst monotherapy users. One study identified polypharmacy to be negatively associated with adherence. Drug side effects were associated with nonadherence $(n=7)$.

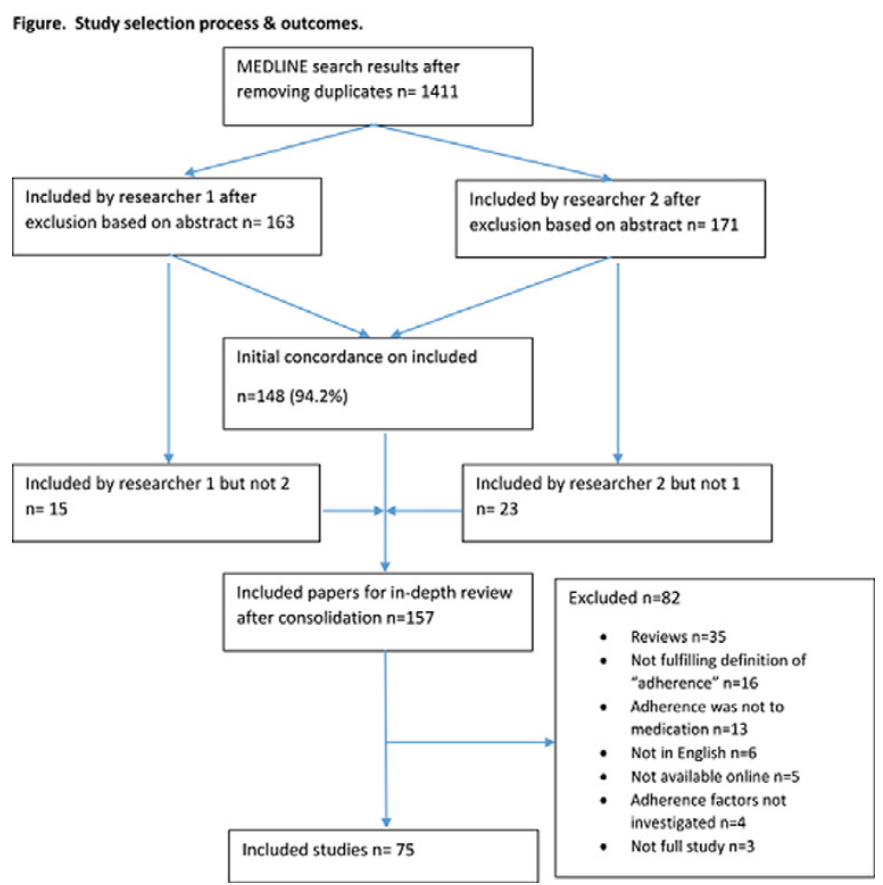

Conclusions: Patient-related factors including personal perceptions were among key contributors to nonadherence to medication in RA patients. This highlights the need for addressing patient-driven perceptions, along with disease and treatment Acknowledgements: Many thanks to Simon Coates and Julia Garthwaite of Library Services at University College London for their advice.

Disclosure of Interest: None declared

DOI: 10.1136/annrheumdis-2017-eular.5137

Abstract THU0072 - Table 1. aSHRs and aHRs for risk of revision, PJI or death following THA/TKA in patients with RA compared with OA; and bDMARD treated RA patients compared with not-bDMARD treated, respectively

\begin{tabular}{|c|c|c|c|c|c|c|}
\hline & \multicolumn{3}{|c|}{ RA $(n=3913)$ vs $O A(n=120499)$} & \multicolumn{3}{|c|}{ bDMARD $(n=360)$ vs no bDMARD $(n=1586)$} \\
\hline & $\begin{array}{c}\text { Revision } \\
\text { aSHR }(95 \% \mathrm{Cl})\end{array}$ & $\begin{array}{c}\text { PJI } \\
\text { aSHR }(95 \% \mathrm{Cl})\end{array}$ & $\begin{array}{c}\text { Death } \\
\text { aSHR }(95 \% \mathrm{Cl})\end{array}$ & $\begin{array}{c}\text { Revision } \\
\text { aSHR }(95 \% \mathrm{Cl})\end{array}$ & $\begin{array}{c}\text { PJI } \\
\text { aSHR }(95 \% \mathrm{Cl})\end{array}$ & $\begin{array}{c}\text { Death } \\
\text { aSHR }(95 \% \mathrm{Cl})\end{array}$ \\
\hline RA vs OA & $0.71(0.57-0.89)^{\dagger}$ & $1.84(1.55-2.18)^{\dagger}$ & $1.58(1.48-1.70)^{\dagger}$ & - & - & - \\
\hline bDMARD treated $\S$ & - & - & - & $0.99(0.40-2.42)$ & $0.94(0.42-2.12)$ & $0.97(0.62-1.51)$ \\
\hline Age at surgery & $0.98(0.98-0.98)^{\dagger}$ & $1.00(0.99-1.00)$ & $1.09(1.09-1.09)^{\dagger}$ & $1.01(0.98-1.03)$ & $1.00(0.97-1.02)$ & $1.10(1.08-1.12)^{\dagger}$ \\
\hline Previous infection w/ hospitalization & $1.48(1.34-1.64)^{\dagger}$ & $1.70(1.53-1.90)$ & $1.50(1.45-1.56)^{\dagger}$ & $0.94(0.38-2.36)$ & $1.56(0.83-2.94)$ & $2.14(1.51-3.02)^{\dagger}$ \\
\hline Chronic obstructive pulmonary disease & $1.17(0.99-1.37)$ & $1.32(1.11-1.56)$ & $1.96(1.86-2.06)^{\dagger}$ & $2.26(0.77-6.64)$ & $1.19(0.41-3.45)$ & $1.08(0.63-1.86)$ \\
\hline Seropositive RA (seronegative as ref.) & - & - & - & $1.33(0.31-5.67)$ & $4.54(0.65-31.67)$ & $1.92(0.92-3.97)$ \\
\hline csDMARD treated $\$$ & - & - & - & $0.77(0.33-1.81)$ & $1.04(0.53-2.02)$ & $0.65(0.44-0.96)^{\dagger}$ \\
\hline Prednisolone treated ${ }^{\S}$ & - & - & - & $1.72(0.80-3.70)$ & $1.18(0.54-2.58)$ & $1.88(1.28-2.76)^{\dagger}$ \\
\hline
\end{tabular}

